\title{
Using Abdominal Massage to Reduce Gastric Residual Volume Among Critically Ill Patients by Nurses in a Tertiary Health Institution in Jos Metropolis, Plateau State
}

\author{
OLUWATOYIN A. OGUNYEWO \\ Department of Nursing Science, University of Jos \\ JULIANA A. AFEMIKHE \\ Department of Nursing Science, University of Benin
}

\begin{abstract}
One of the major problems of hospitalized critically ill patients is nutrition. Meeting the daily nutritional requirements to prevent malnutrition and problem related to it. Early enteral feeding is recommended as first line of nutrition therapy for critically ill patients, although enteral feeding is often complicated with intolerance and aspiration as a result of high gastric residual volume. Abdominal massage is a technique used in improving digestive function. The aim of this study was to determine the knowledge and practice of abdominal massage as a means of reducing gastric residual volume (GRV) in critically ill patients among nurses and doctors. This was a descriptive, cross-sectional and non-experimental study. This study sample comprised 73 nurses in the units where critically ill patients are kept such as Intensive Care Unit (ICU), High Dependency Unit (HDU), Special Care Baby Unit (SCBU), and Neuro-Surgery department of Jos University Teaching Hospital, Jos. Questionnaire was the instrument used to elicit responses from the respondents. The study was carried out within the ambit of the range of ethics considerations. Convenience sampling technique was adopted in gaining access to the participants. Findings from this study reveal the importance of the use of abdominal massage, and the non-practice of the method in addressing abdominal problems, even though, awareness of it was high. Reasons attributable to use of other means such as aspiration of excess GRV with NG tube were provided. There was poor knowledge of the signs of high GRV that would necessitate abdominal massage.
\end{abstract}

Keywords: Abdominal massage, critically ill patients, nurses, gastric residual volume,

DOI: $10.7176 / \mathrm{JBAH} / 10-14-03$

Publication date:July $31^{\text {st }} 2020$

\section{INTRODUCTION}

The gastric residual volume of critically ill patients requires monitoring to avoid the risk of gastrointestinal (GI) dysfunctions such as decreased peristalsis, decrease bowel transit period. Pulmonary aspiration, regurgitation and ventilator-associated pneumonia could emanate from these dysfunctions. Early enteral nutrition is recommended as first line of nutrition therapy in critically ill patients, since it provides both nutritional and non-nutritional benefits. (Gunner, Thomas \& Daren, 2017). Notwithstanding, enteral nutrition is inclined toward compromised gastro-intestinal functions. The use of gastric residual volume (GRV) in detecting GI dysfunction is considered a substitute means of determining limit in the course of enteral nutrition periodically, therefore, clinicians use GRV monitoring to discern reduced gastric emptying, and in making early intervention in order to minimize the concomitant risks of enteral feeding among patients (Gunner, Thomas \& Daren, 2017). Abdominal massage is an ancient remedy used in treating issues pertaining to the abdominal areas, massage is extremely beneficial to the body and therapeutic to the mind, massaging the leg after a run helps lactic acid move to reduce soreness and massaging a stiff neck and shoulder helps reduce tension. Massaging the abdomen improve digestion and relieve stress which improve GI function (Edward, 2013). Abdominal massage is a gentle, non-invasive treatment that may have relaxing and healing effect for some people, and are used in the treatment of wide variety of health conditions especially those related to the stomach such as indigestion and bloating (Daniel, 2018). Massage therapy can stimulate the parasympathetic activity and induce a more effective gastro-intestinal function by increasing peristalsis, decrease abdominal distension, increase bowel transit time, reduce gastric gas volume, increase frequency of defecation and decrease the frequency of vomiting. Thus, abdominal massage is intended to improve digestive system function (Mahin, et al., 2014). Stomach massage is not only helpful in relieving stress but also improve oxygen circulation through blood in necessary area and body fluid which ensures the body secret enough enzymes for clearing bowel and prevent constipation as well as other benefits such as reducing irregular menstrual pain and reboot internal organs (Pramod, 2017).

Statement of the problem

The importance of abdominal massage in relieving abdominal problems, especially among the critically ill patients has been established by a number of studies carried out in that direction. It is equally documented that this practice 
was the dominant intervention in American health care delivery context in the 60s before it became unpopular as a result of other advanced competing alternatives (Westman \& Blaisdell, 2016). Its revival in the contemporary times is an evidence of its time-honored relevance. In Nigeria, there is a paucity of literature as to show whether this abdominal massage is being practiced, and also, whether nurses have the knowledge and understanding of its inherent techniques. This study was predicated on this gap which the researchers were inclined to address.

\section{Objectives of the study}

1. Assess the knowledge of abdominal massage among nurses in Jos University Teaching Hospital.

2. Determine the level of practice of abdominal massage among nurses in reducing gastric residual volume in Jos University Teaching Hospital

3. Determine the factors hindering the effective practice of abdominal massage among nurses in Jos University Teaching Hospital

\section{MATERIALS AND METHODS}

This study was a cross sectional, descriptive research and non-experimental one aimed at addressing the objectives raised. The study setting for this study was Jos University Teaching Hospital situated in the Jos North Local Government Area of Plateau State. Jos city has a population of about 900,000 (NPC, 2006). The city is about 1,238 meters (4,062 feet) above the sea level in terms of elevation. JUTH is a tertiary health institution primarily meant for teaching and research. The hospital has various departments that coordinately function toward achieving its primary aim. Four clinical units where critically ill patients are admitted were selected for this study. These units were Intensive Care Unit (ICU), High Dependency Unit (HDU), Special Care Baby Unit (SCBU) and NeuroSurgery Unit. The population of this study consisted nurses who were working in those units and, directly involved with critically ill patients. Selecting a sample randomly was a bit challenging as some of the practitioners were on either annual leave or a study leave thereby making convenience sampling technique a better alternative. The instrument for data collection was questionnaire consisting both socio-demographic profile, and items on the different segments of practice of abdominal massage. A total of 77 copies of questionnaire were distributed to the respondents and 73 were retrieved accounting for $94.8 \%$ of the response rate of the study population.

\section{RESULTS}

The data collected for the study were presented in tables below.

Table 1: Socio demographic data

\begin{tabular}{llcc}
\hline Item & Option & F. & \% \\
\hline Age & $20-29$ years & 18 & 24.7 \\
& $30-39$ & 25 & 34.2 \\
& $40-49$ & 10 & 13.7 \\
Total & 50 and above & 20 & 27.4 \\
Sex & Male & $\mathbf{7 3}$ & $\mathbf{1 0 0}$ \\
& Female & 33 & 45.2 \\
Total & & 40 & 54.8 \\
Religion & Christianity & $\mathbf{7 3}$ & $\mathbf{1 0 0}$ \\
& Muslim & 65 & 89 \\
& Traditional & 8 & 11 \\
Total & Others (specify) & 0 & 0 \\
Marital status & & 0 & 0 \\
& Single & $\mathbf{1 0 0}$ \\
& Married & $\mathbf{7 3}$ & 31.5 \\
& Divorced & 23 & 65.8 \\
Total & Separate & 48 & 0 \\
Ethnic group & Widow & 0 & 2.7 \\
& & 2 & 0 \\
& Ngas & 0 & $\mathbf{1 0 0}$ \\
& Taroh & $\mathbf{7 3}$ & 16.4
\end{tabular}




\begin{tabular}{llccc}
\hline Item & Option & F. & \% \\
\hline Occupational & experience & $0-4$ & 19 & 26 \\
(years) & $5-9$ & 20 & 27.4 \\
& $10-14$ & 8 & 11 \\
& $15-19$ & 6 & 8.2 \\
Total & 20 and above & 20 & 27.4 \\
& & $\mathbf{7 3}$ & $\mathbf{1 0 0}$ \\
\hline
\end{tabular}

Table 1 shows that, majority, 25 (32.2\%) of the respondents were within the age group 30-49 years, followed by 50 years and above $20(27.4 \%), 20-29$ years were $18(24.7 \%)$ and $40-49$ years were $10(13.7 \%)$. More than half of the respondents were females $40(54.8 \%)$ while males were $33(45.2 \%)$. Religious distribution shows that 65 $(89 \%)$ are Christians while Muslim respondents were $8(11 \%)$. Marital distribution indicates that $48(65.8 \%)$ of the respondents were married: Single $23(31.5 \%)$, and $2(2.7)$ were separated. Respondents from Ngas are 12 (16.4\%), Taroh, $2(2.7 \%)$, Berom $8(11 \%)$, Igbo (3\%), Hausa $6(8.2 \%)$, Yoruba $15(20.5 \%)$ while respondents from other ethnic group were 27 (37\%). Occupational experience distribution shows that $0-4$ years were $19(26 \%)$, 5-9 years, $20(27.4 \%), 10-14$ years, $8(11 \%), 15-19$ years, $6(8.2 \%)$ while 20 years and above were $20(27.4 \%)$.

Table 2: Knowledge of abdominal massage

\begin{tabular}{|c|c|c|c|c|}
\hline & Item & Option & $\mathrm{F}$ & $\%$ \\
\hline \multirow[t]{3}{*}{1.} & Have you heard of abdominal & Yes & 38 & 52.1 \\
\hline & massage? & No & 35 & 47.9 \\
\hline & Total & & 73 & 100 \\
\hline \multirow[t]{7}{*}{2.} & If yes (in 8) what is your source of & Lecture & 7 & 9.6 \\
\hline & knowledge? & Medical books & 11 & 15.1 \\
\hline & & Seminar/workshop & 4 & 5.5 \\
\hline & & Journal & 8 & 11 \\
\hline & & Clinical practice & 17 & 23.3 \\
\hline & & Others & 4 & 5.5 \\
\hline & Total & & 73 & 100 \\
\hline \multirow[t]{7}{*}{3.} & What volume of gastric residual & $<100 \mathrm{mls}$ & 4 & 5.5 \\
\hline & volume that would necessitate & $100-200 \mathrm{mls}$ & 4 & 5.5 \\
\hline & performing abdominal massage? & $201-400 \mathrm{mls}$ & 6 & 8.2 \\
\hline & & $401-500 \mathrm{mls}$ & 8 & 11 \\
\hline & & $>500 \mathrm{mls}$ & 8 & 11 \\
\hline & & No idea & 43 & 58.9 \\
\hline & Total & & 73 & 100 \\
\hline \multirow[t]{7}{*}{4.} & What is the sign(s) of high GRV that & Vomiting & 17 & 23.3 \\
\hline & would require abdominal massage? & Regurgitation & 19 & 76.7 \\
\hline & & Aspiration & 20 & 27.4 \\
\hline & & Reduce frequency of defecation & 15 & 20.5 \\
\hline & & No idea & 37 & 49.3 \\
\hline & & Others & 0 & 0 \\
\hline & Total & & 73 & 100 \\
\hline \multirow[t]{7}{*}{5} & What patients are contra-indicated & Pregnant women & 40 & 54.8 \\
\hline & for abdominal massage? & Children & 2 & 2.7 \\
\hline & & Critically ill patients & 10 & 13.7 \\
\hline & & Intestinal obstruction & 22 & 30.1 \\
\hline & & No idea & 21 & 28.8 \\
\hline & & Others & 0 & 0 \\
\hline & Total & & 73 & 100 \\
\hline
\end{tabular}

Table 2 reveals that a little above half of the respondents 38 (52.1\%) were aware of abdominal massage, 35 (47.9\%) had not heard of abdominal massage. Major sources of information of those that had heard of abdominal massage were clinical practice $17(23.3 \%)$, medical and nursing books $11(15.1 \%)$, lecture $7(9.6 \%)$, journals 8 $(11 \%)$, and $4(5.5 \%)$ were from other sources.

Majority of the respondents $43(58.9 \%)$ had no idea on the volume of GRV that would necessitate abdominal massage, $4(5.5 \%)$ each indicated less than $100 \mathrm{mls}$ and $100-200 \mathrm{mls}, 6(8.2 \%) 201-400 \mathrm{mls}, 8(11 \%)>500 \mathrm{mls}$. Most, $37(49.3 \%)$ of the respondents had no idea of the signs of high GRV that would necessitate abdominal massage, $20(27.4 \%)$ indicated aspiration, regurgitation 19 (76.7\%), vomiting 17 (23.3\%), and reduced frequency of defecation $15(20.5 \%)$.

Majority $40(54.8 \%)$ claimed that contraindications for abdominal massage were pregnant women, intestinal obstruction, 22 (30.1\%) critically ill, $10(13.7 \%)$, children, $2(2.7 \%)$ while $21(28.8 \%)$ of the respondents had no 
idea.

Table 3: Practice of abdominal massage

\begin{tabular}{|c|c|c|c|}
\hline Item & Option & $\mathrm{F}$ & $\%$ \\
\hline 1. Do you practice abdominal massage? & Yes & 8 & 10.9 \\
\hline & No & 65 & 89 \\
\hline Total & & 73 & 100 \\
\hline
\end{tabular}

2. If no, why?

a. My institution does not approve the use of abdominal massage in reducing gastric $\quad$ Yes $\quad 22 \quad 30.1$

residual volume.

No $\quad 51 \quad 69.9$

Total5

b. We use other means to reduce gastric residual volume

$\begin{array}{lll} & 73 & 100 \\ \text { Yes } & 53 & 72.6 \\ \text { No } & 20 & 27.4 \\ & 73 & 100 \\ \text { Yes } & 35 & 47.9 \\ \text { No } & 38 & 52.1 \\ & 73 & 100 \\ \text { Yes } & 16 & 21.9 \\ \text { No } & 57 & 78.1 \\ & 73 & 100 \\ \text { Yes } & 12 & 16.4 \\ \text { No } & 61 & 83.6\end{array}$

e. Abdominal massage is not effective in reducing gastric residual volume in

Total

f. Others

Total

3. Does abdominal massage reduce gastric residual volume

Total

4. What is your duration of abdominal massage?

a. I do not carry out abdominal massage

Yes $\quad 50 \quad 68.5$

Total

b. Less than 5 minutes

No $23 \quad 31.5$

\section{Total}

c.5-10 minutes

$\begin{array}{lrl} & 73 & 100 \\ \text { Yes } & 10 & 13.7 \\ \text { No } & 63 & 86.3 \\ & \mathbf{7 3} & \mathbf{1 0 0} \\ \text { Yes } & 4 & 5.5 \\ \text { No } & 69 & 94.5 \\ & \mathbf{7 3} & \mathbf{1 0 0} \\ \text { Yes } & 4 & 5.5 \\ \text { No } & 69 & 94.5 \\ & \mathbf{7 3} & \mathbf{1 0 0} \\ \text { Yes } & 4 & 5.5 \\ \text { No } & 69 & 94.5 \\ & \mathbf{7 3} & \mathbf{1 0 0}\end{array}$

Total

d. 15 minutes

Total

e. More than 15 minutes

\section{Total}

Yes $\quad \begin{array}{lll}10 & 13.7\end{array}$

$\begin{array}{lll}\text { No } \quad 63 & 86.3\end{array}$

Total

$73 \quad 100$

Table 3 reveals most, $65(89 \%)$ of the respondents do not practice abdominal massage, $8(11 \%)$ of the respondents claimed they practiced abdominal massage. The reasons given for not practicing abdominal massage were: the use other means to reduced GRV 53 (72.6\%), no approval from institution, $22(30.1 \%)$, the health workers do not know how to carry out abdominal massage $35(47.9 \%)$, it is not practiced in Nigeria $16(21.9 \%)$, ineffectiveness of abdominal massage $12(16.4 \%)$ while $4(5.5 \%)$ cited other reasons. Majority, 51 (69.9\%) of the respondents indicated that abdominal massage reduces gastric residual volume, $22(30.1 \%)$ respondents differed. Fifty $(68.5 \%)$ of the respondents do not carry out abdominal massage process, while out of those who practice it, the duration of the session was less than 5 minutes as indicated by $10(13.7)$ respondents, $5-10$ minutes, 4 (5.5\%) 
respondents, 15 minutes, $4(5.5 \%)$ respondents and $>15$ minutes, 4 (5.5\%) respondents. A substantial number, 63 $(86.3 \%)$ claimed that do not measure GRV before performing abdominal massage because it was not a usual practice while $10(13.7 \%)$ asserted they measure GRV before abdominal massage.

Table 4: Practice of abdominal massage (b)

\begin{tabular}{|c|c|c|c|}
\hline Item & Option & $\mathrm{F}$ & $\%$ \\
\hline \multicolumn{4}{|l|}{ What do you observe during abdominal massage? } \\
\hline a. I start my abdominal massage from the right iliac region to & Yes & 4 & 5.3 \\
\hline relieve congestions & No & 69 & 94.5 \\
\hline Total & & 73 & 100 \\
\hline \multirow{2}{*}{ b. I use the tip of my fingers to move in deeper } & Yes & 6 & 8.2 \\
\hline & No & 67 & 91.8 \\
\hline Total & & 73 & 100 \\
\hline \multirow{2}{*}{ c. I move the patient legs towards the belly } & Yes & 8 & 11 \\
\hline & No & 65 & 65 \\
\hline Total & & 73 & 100 \\
\hline \multirow{3}{*}{$\begin{array}{l}\text { d. I use fingertip to massage the abdomen, moving inward and } \\
\text { downward } \\
\text { Total }\end{array}$} & Yes & 0 & 0 \\
\hline & No & 73 & 100 \\
\hline & & 73 & 100 \\
\hline \multirow[t]{2}{*}{ e. I go deeper with the finger tip } & Yes & 10 & 13.7 \\
\hline & No & 63 & 86.3 \\
\hline Total & & 73 & 100 \\
\hline f. With one hand over the other, I repeat the motion anti- & Yes & 0 & 0 \\
\hline clockwise in smaller cycles & No & 73 & 100 \\
\hline Total & & 73 & 100 \\
\hline \multirow[t]{2}{*}{ g. I repeat the stroking movement for $10-15$ minutes } & Yes & 6 & 8.2 \\
\hline & No & 67 & 91.8 \\
\hline Total & & 73 & 100 \\
\hline \multirow[t]{2}{*}{ h. I apply gentle pressure on areas that feels tender } & Yes & 8 & 11 \\
\hline & No & 65 & 89 \\
\hline Total & & 73 & 100 \\
\hline
\end{tabular}

Data on procedure for abdominal massage shows that $4(5.5 \%)$ start abdominal massage from the right iliac region to relieve congestions, $6(8.2 \%)$ use the tip of their fingers to move in deeper, $8(11 \%)$ move the patient legs towards the belly, $10(13.7 \%)$ go deeper with the finger tip, $6(8.2 \%)$ repeat the stroking movements for 10 15 minutes while $8(11 \%)$ apply gentle pressure on areas that feel tender. 
Table 5: Practice of abdominal massage (c)

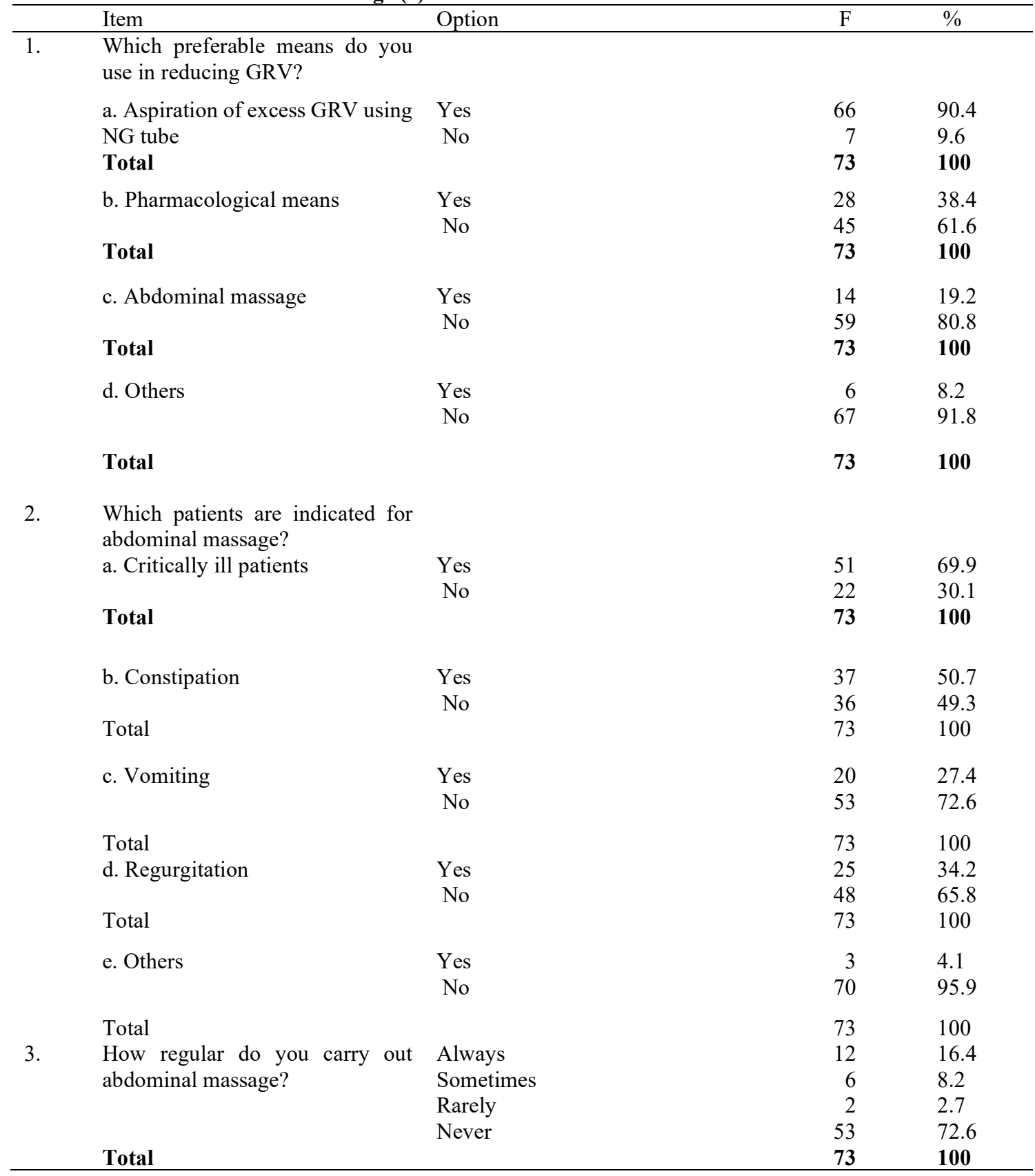

Table 5 reveals that, $66(90.4 \%)$ conceded that the most preferably means of reducing GRV were aspiration of excess GRV using NG tube, 28 (38.4\%), pharmacological means, 14 (19.2\%) abdominal massage, and 6 (8.2\%) used other means. 51 (69.9) concurred that patients mostly indicated for abdominal massage the critically ill, 37 $(50.7 \%)$ constipation, $25(34.2 \%), 20(27.4 \%)$ vomiting, $25(34.5 \%)$ regurgitation, and $3(4.1 \%)$ indicated others. Over two third, $53(73.2 \%)$ claimed they have never carried out abdominal massage, $12(16.4 \%)$ claimed they carry it out always, $6(8.2 \%)$ sometimes, $2(2.7 \%)$ rarely practiced abdominal massage. 
Table 6: Factors influencing the practice of abdominal massage

\begin{tabular}{|c|c|c|c|c|}
\hline & Item & Option & $\mathrm{F}$ & $\%$ \\
\hline \multirow[t]{3}{*}{1.} & Hospital policy which do not approve the use of abdominal & Yes & 54 & 74 \\
\hline & massage & No & 19 & 26 \\
\hline & Total & & 73 & 100 \\
\hline \multirow[t]{3}{*}{2.} & Poor research in abdominal massage as a means of reducing gastric & Yes & 70 & 95.9 \\
\hline & residual & No & 30 & 4.1 \\
\hline & Total & & 73 & 100 \\
\hline \multirow[t]{3}{*}{3.} & Experience level of health workers in abdominal massage & Yes & 52 & 71.2 \\
\hline & & No & 21 & 28.8 \\
\hline & Total & & 73 & 100 \\
\hline \multirow[t]{4}{*}{4.} & Abdominal massage is not within my training curriculum & Yes & 36 & 49.3 \\
\hline & & No & 35 & 47.3 \\
\hline & & Invalid & 2 & 2.7 \\
\hline & Total & & 73 & 100 \\
\hline \multirow[t]{3}{*}{5 . } & Poor outcome of abdominal massage & Yes & 30 & 41.1 \\
\hline & & No & 43 & 58.9 \\
\hline & Total & & 73 & 100 \\
\hline \multirow[t]{3}{*}{6.} & Ethical issues & Yes & 47 & 64.4 \\
\hline & & No & 26 & 35.6 \\
\hline & Total & & 73 & 97.3 \\
\hline
\end{tabular}

Table 6 reveals the factors influencing the practice of abdominal massage as included: hospital policy, 54 (74\%), experience level of health workers on abdominal massage $52(71.2 \%)$, none inclusion on training curriculum $36(49.3 \%)$, poor research on abdominal massage $70(95.9 \%)$, poor outcome of abdominal massage 30 (41.1\%) and ethical issues 47 (64.4\%).

Table 7: Chi square analysis of hypothesis 1

\begin{tabular}{|l|l|l|l|l|}
\hline Item & Cal value & Df & Critical value & P value \\
\hline Knowledge and practice of abdominal massage among nurses & 8.413 & 1 & 3.841 & 0.05 \\
\hline
\end{tabular}

The chi-square analysis of the relationship between knowledge and practice among nurses shows that the result is highly significant.

\section{DISCUSSION}

Nurses have always had knowledge of abdominal massage as evidenced in this study. This was corroborated by Kathryn (2016) who revealed that nurses' possession of the knowledge of abdominal massage predated the contemporary times even though there was no enough evidence to show its approval in nursing practice. Findings of this study further show that the respondents do not practice abdominal massage as there were other means of effecting such. This is consistent with the evidence provided by Norma (2008), Venessa, (2018) which indicated that most nurses uses aspiration of excess GRV and drugs. The assertion by respondents that abdominal massage reduces gastric residual volume in critically ill patients is supported by Farzad (2018) in a controlled trial study in which it was revealed that abdominal massage reduces gastric residual volume in patients. Other studies like Mc Clurg (2016), Mannal et al (2010), Nurcal, et al (2012) conducted among adults, children, constipated patients and critically ill provide further evidence in support of reduced GRV after performing abdominal massage. Respondents in this study claimed that they use NG tube for the aspiration of excess gastric residual volume to reduce gastric residual volume. This finding aligns with Venessa et al., (2018) Norma (2008) whose studies show that practitioners make use of NG tube to reduce gastric residual volume. Respondents further indicated that critically ill patients have benefitted from abdominal massage just as those that suffer from constipation, vomiting or regurgitation are not left out in this use of abdominal massage. Findings of the studies by McClurg et al (2016), Farzad et al (2018), Nurcan, et al., (2012) further lend support to this outcome. Most of the respondents rarely perform abdominal massage this may be due to poor knowledge on abdominal massage procedure and poor research. This is supported by the findings by Westman and Blaisdell (2016) which emphasize that some nurses and hospitals have integrated abdominal massage into routine nursing practice however many hospitals have not yet. The findings on the factors affecting poor of abdominal massage align with the outcome of the study by Westman and Blaisdell (2016) which implicated poor research, hospital policy, funding, massage therapy training and tracking the effectiveness. The study also reveals that there was significant relationship between knowledge and practice of abdominal massage among nurses in reducing gastric residual volume. The assertion of Westman 
and Blaisdell (2016) lends support to this finding as it emphasizes that massage therapy was once part of core nursing skills before it waned as a result of changes in nursing technology. The second hypothesis is not significant. This, following from the above scholars' assertion, could be linked to the fact that abdominal massaging did take a place of prominence in the medical knowledge.

\section{CONCLUSION}

The study attempted to determine the knowledge of abdominal massage and its practice among nurses in Jos University Teaching Hospital. The outcome of the study reveals the state of the art. Study limitations were well acknowledged. Ordinarily, this study should have been extended to primary and secondary health tiers in order to foster some form of cumulative knowledge.

\section{REFERENCES}

Daniel, B. (2018). Why you should massage your stomach and how to do it? Healthline. Accessed date may 2, 2018.

Edward Group, (2013). How to perform abdominal massage. Global Healing Centre.https:/www.globalhealingcentre.com/natural-health/how-to-perform-abdominal-massage

Farzad, M, Alireza A, Nader S, Ali S, Behzad hemmatpour, (2018). Studying the effect of abdominal massage on the patients gastric residual volume in patients hospitalized in intensive care unit. Journal of Intensive Care, 6:47 https://doi.org/10.1186/s40560-018-0317-5

Gunner E, Thomas W.F, Daren K.H. (2014). Gastric residual volume in critically patients Nutrition in Clinical Practice. Wiley online library. https://doi.org/10.1177/0884533614562841

Mahin S, Ahmad G, Mahboubeh V, Amir M, Armanian, S, Amini R. (2017). Effect of abdominal massage on feeding tolerance in preterm infants hospitalized. International Journal of Pediatrics, 5 (3) 39:503-4510 DOI: $10.22038 /$ ijp.2017.21376.1795

McClurg, D, Hagen, S, Jamieson, K, Dickinson, L, Paul, L and Cunnington, A. (2016).

Abdominal massage for the alleviation of symptoms of constipation in people with parkinson's: A randomized controlled pilot study. Age and ageing, 45 (2), pp 299-303.

Nurcan U, Ismet E, Hale A Akpinar. (2012). The effect of abdominal massage on gastric residual volume. Gastroenterology Nursing: the official journal of the society of Gastroenterology Nurses and Associates 35 (2): $117-$ 23 DOI:10.1097/SGA.0b013e31824c235. Accessed date $15^{\text {th }}$ August, 2018.

Pramod K, (2017). Benefits of stomach massage for constipation, gas and weight loss. E pain Assist Publication.

Vannesa D. B, Proveda, A C, Lilia D, Reneta E, Rita D (2018). Assessing gastric residual volume. A description of nurses. Clinical Practice E pub. ISSN; 0080-6234

Westman K F., Blaidsdell, C (2016). Many benefits, little risk: the use of abdominal massage in nursing practice. American Journal of Nursing; 116; 34-39 